\title{
Synthesis of Colibactin Pyrrolidono[3,4-d]pyridones via Regioselective C(sp3)-H Activation
}

\author{
Ilazi, Agron ; Huang, Bin ; de Almeida Campos, Valery ; Gademann, Karl
}

\begin{abstract}
The synthesis of pyrrolidono[3,4-d]pyridones of relevance to putative genotoxic colibactin structures featuring a doubly conjugated 1,6-Michael acceptor system is reported. We investigated and implemented a highly selective $\mathrm{Pd}$-catalyzed $\mathrm{C}(\mathrm{sp} 3)-\mathrm{H}$ activation reaction as a key step and further functionalized the pyridone core. Evaluating the role of this structural unit of relevance to colibactin, we found that this structure displayed a high degree of stability toward both acidic conditions and nucleophiles.
\end{abstract}

DOI: https://doi.org/10.1021/acs.orglett.0c02385

Posted at the Zurich Open Repository and Archive, University of Zurich

ZORA URL: https://doi.org/10.5167/uzh-196834

Journal Article

Accepted Version

Originally published at:

Ilazi, Agron; Huang, Bin; de Almeida Campos, Valery; Gademann, Karl (2020). Synthesis of Colibactin Pyrrolidono[3,4-d]pyridones via Regioselective C(sp3)-H Activation. Organic Letters, 22(17):6858-6862. DOI: https://doi.org/10.1021/acs.orglett.0c02385 


\title{
Synthesis of Colibactin Pyrrolidono[3,4-d]pyridones via Regioselective C(sp $\left.{ }^{3}\right)-H$ Activation
}

\author{
Agron Ilazi, Bin Huang, Valery de Almeida Campos, and Karl Gademann*
}

The synthesis of pyrrolidono[3,4- $d$ ]pyridones of relevance to putative genotoxic colibactin structures featuring a doubly conjugated 1,6-Michael acceptor system is reported. We investigated and implemented a highly selective Pd-catalyzed C( $\left.\mathrm{sp}^{3}\right)$ $\mathrm{H}$ activation reaction as a key step and further functionalized the pyridone core. Evaluating the role of this structural unit of relevance the colibactin, we found that this structure displayed a high degree of stability towards both acidic conditions and nucleophiles.

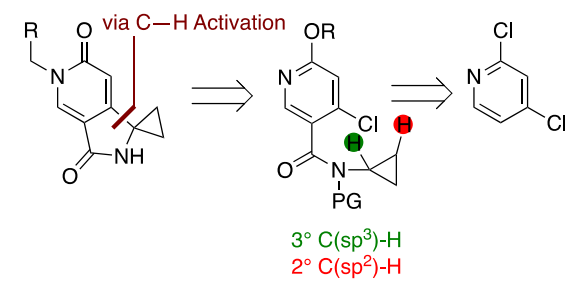

The term 'human microbiota' refers to a wide range of different microorganisms such as bacteria, fungi, and viruses residing in and on the human body and have been implied as human's second genome.[1] Little is known about their inter-kingdom interaction and their effect on human health or disease progression.[2] Recently, the bacteria Helicobacter pylori and Klebsiella oxytoca have been identified to induce colitis, albeit by different mechanisms.[3] Over a decade ago, the Oswald group reported that certain commensal and extra-intestinal $E$. coli strains of the phylogenetic group B2 can cause megalocytosis and cell cycle arrest.[4] These scientists identified and linked cytotoxicity to a 54 kilobase $p k s$ genomic island harboring a hybrid non ribosomal peptide synthetase-polyketide synthase NRPS-PKS and provided evidence for the whole gene cluster linked to its cytotoxicity.[4]
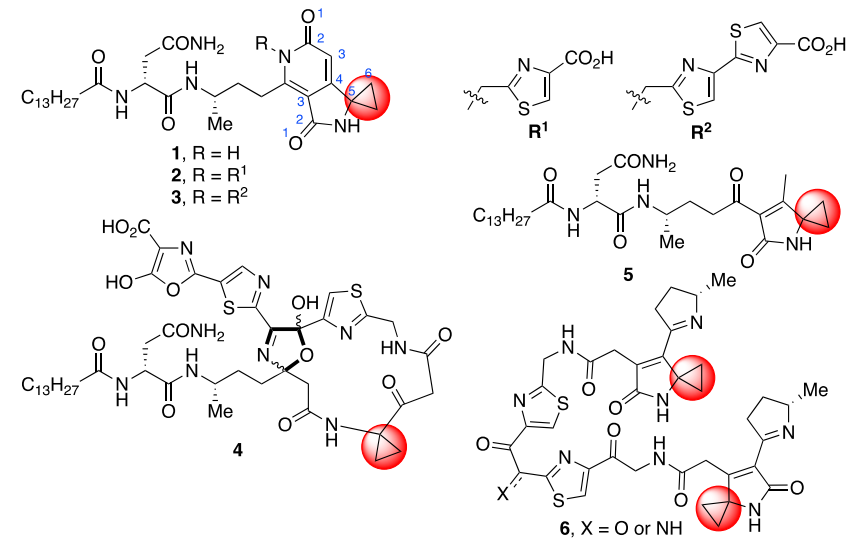

Figure 1. Natural compounds isolated from the clb E. coli strain of putative relevance to the (pre)-colibactin structure of pKs island.

Over the last fifteen years, the isolation and characterization of the small molecule compounds resulting from this cluster (the so-called (pre)-colibactins) proved to be challenging, presumably due to their instability, difficulties in heterologous expression, and fermentation (Figure 1).[5] A number of metabolites such as the pyridone 1, the monothiazole substituted $\mathbf{2}$, the bisthiazole substituted $\mathbf{3}$, and the complex macrocycle $\mathbf{4}$ have been isolated.[5] Furthermore, the lactam 5 was proposed to bear the colibactin warhead [5a] and the recently proposed active genotoxic metabolite $6[5 \mathrm{i}, \mathrm{h}]$ have been characterized and linked to the $p k s$ island and/or its mutants. Seminal synthetic and reactivity studies by Herzon,Crawford, and their co-workers led them to conclude that compounds similar to lactam 6, albeit monomeric, and not pyridones such as 1-3 alkylate DNA, with the pyridones being stable.[5k] All these structures feature a cyclopropyl ring (Figure 1, highlighted) in conjugation with 1,4-or 1,6-Michael acceptors, thereby likely increasing their electrophilic character. Another feature of these compounds includes a prodrug mechanism, where a $\mathrm{clb}$ encoded peptidase cleaves the $\mathrm{N}$-myristoyl-D-asparagine moiety to generate compounds with higher activity and reactivity.[6, 7] In the context of recent studies of pyridones as neuritogenic compounds by us and others,[8] and the prevalence of pyridone containing natural products and pharmacophores, [9] we directed our attention to pyrrolidono[3,4-d]pyridones 1-3, as these complex heterocyclic compounds have incorporated the cyclopropyl ring in a unique double 1,6-relationship through conjugation, rendering them structurally interesting Michael acceptors. In addition, Michael acceptors and other covalent modifiers gained strong interest in drug discovery efforts over the last years.[10] In addition to these biological questions and structural requirements for addition, we were also interested in identifying a novel route towards these compounds, which should facilitate the access to the target structure and derivatives for chemical and biological evaluation. Therefore, we report on a novel access to this class of compounds via a regioselective, $\mathrm{Pd}$-catalyzed $\mathrm{C}\left(\mathrm{sp}^{3}\right)-\mathrm{H}$ activation approach.[11]

Scheme $1 \mathrm{C}-\mathrm{H}$ functionalization of cyclopropyl amides via Pd catalysis.

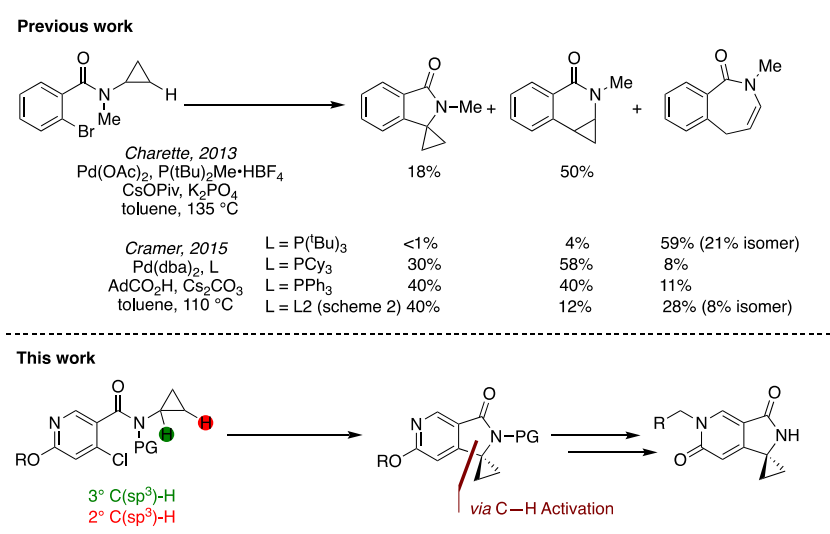

The development and application of powerful C-H activation methodologies has gained tremendous interest and been successfully imple- 
mented in many synthetic endeavors.[12] Promising literature precedents for C-H functionalization of cyclopropyl amides (Scheme 1) led us to examine this synthetic approach. Fagnou and co-authors demonstrated the superiority of a soluble organic additives like pivaloic acid for $\mathrm{C}-\mathrm{H}$ activation protocols and his group established a $\mathrm{C}-\mathrm{H}$ functionalization of cyclopropyl carbamates leading to quinolines after oxidation.[13] The group of Charette observed in 2013 that cyclopropyl benzamides are less prone to ring-opening in the presence of external bases.[14] Cramer and coworkers investigated the effect of ligands and a 1:1 ratio between methine and methylene $\mathrm{C}-\mathrm{H}$ bond cleavage was obtained with triphenylphosphine as ligand and 1-adamantanecarboxylate as base. [15] In all previous literature studies, the desired five membered compounds were never obtained as major products. From all these observations, the following challenges had to be overcome in the context of this study: (1) The different electronic nature of pyridine amides when compared to benzene derivatives; (2) use of chloro- instead of more reactive bromo-precursors, (3) successfully addressing the regioselectivity bias, and favor methine over methylene $\mathrm{C}-\mathrm{H}$ activation; and (4) suppressing the inherent susceptibility of the cyclopropyl group for ring opening. The chloro substituent was preferred over the more reactive bromo or iodo substituents, as we sought to first introduce amide or carboxylate groups by cross coupling or halogenmetal exchange on the $\mathrm{C}-\mathrm{Br}$ bond before the $\mathrm{C}-\mathrm{H}$ activation step (vide infra).

Scheme 2. Investigation of the $\mathrm{C}-\mathrm{H}$ activation reaction on a model substrate (TMB = 3,4,5-trimethoxybenzyl).

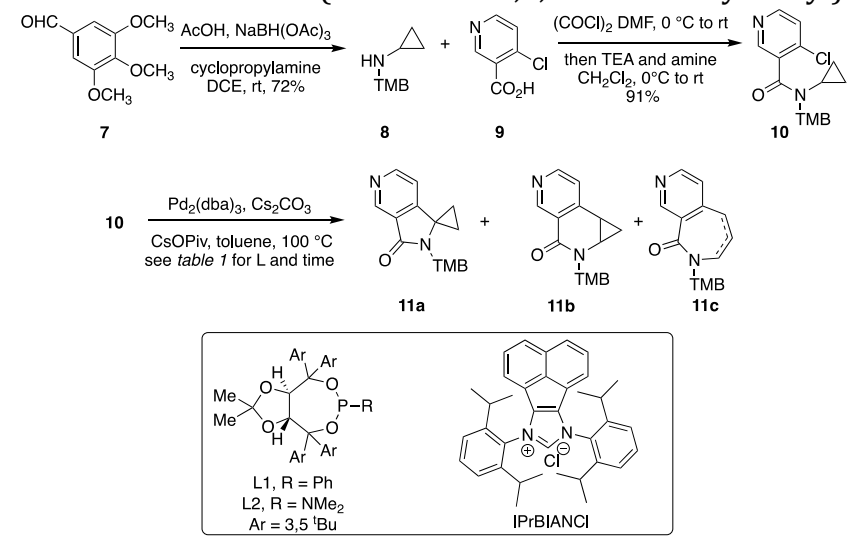

Table 1. Conditions for the key $\mathrm{C}-\mathrm{H}$ activation reaction on a model substrate.

entry ligand time result

(h)

11a:11b:11c ${ }^{a}$

(isolated yield \%)

\begin{tabular}{c|c|c|c}
\hline $\mathbf{1}$ & $\mathrm{PCу}_{3} \bullet \mathrm{HBF}_{4}$ & 21 & $1: 5.5: 0(83 \%)$ \\
\hline $\mathbf{2}$ & $\mathrm{IPrCl}$ & 16 & $1: 2: 0$ \\
\hline $\mathbf{3}$ & $\mathrm{SIPrBF}_{4}$ & 16 & $1.2: 1: 0(86 \%)$ \\
\hline $\mathbf{4}^{\boldsymbol{b}}$ & IAdBF $_{4}$ & 17 & $2.2: 0: 1(45 \%)$ \\
\hline $\mathbf{5}$ & IPrBIANCl & 16 & $1: 2.8:$ n.d \\
\hline $\mathbf{6}$ & $\mathrm{L} 1$ & 22 & n.d \\
\hline $\mathbf{7}$ & $\mathrm{L} 2$ & 22 & n.d \\
\hline
\end{tabular}

${ }^{a}$ ratio determined by analysis reaction mixtures by ${ }^{1} \mathrm{H}$ NMR spectroscopy. ${ }^{b} 105^{\circ} \mathrm{C} 1 \mathrm{~h}$ and $110^{\circ} \mathrm{C} 15 \mathrm{~h}$

The challenges listed above were first investigated in the context of a model substrate, which was synthesized in two steps. Reductive amination of 3,4,5-trimethoxybenzaldehyde $\mathbf{7}$ with cyclopropyl amine using triacetoxyborohydride gave the secondary amine 8 in $72 \%$ yield [16]. 4-Chloronicotinic acid 9 was converted in situ to the corresponding acyl chloride $\left((\mathrm{COCl})_{2}\right.$, cat. DMF), subsequent addition of 8 in the presence of triethylamine furnished amide 10 (91\%).[18] With the intermediate $\mathbf{1 0}$ in hand, the stage for the $\mathrm{C}-\mathrm{H}$ functionalization was set and the results are summarized in Table 1 Literature reports suggest that the role of the ligand has the strongest influence on the outcome of the reaction, while other parameters such as Pd source, base, additive, and solvent were based on recent findings. [14-15] The following parameters were set, $\mathrm{Pd}_{2} \mathrm{dba}_{3}, \mathrm{Cs}_{2} \mathrm{CO}_{3}$, $\mathrm{Cs} \mathrm{OPiv}$ as soluble organic base, toluene as solvent and generally a temperature of $100^{\circ} \mathrm{C}$ was kept, since it was sufficient for the reactivity. The electron rich $\mathrm{PCy}_{3} \bullet \mathrm{HBF}_{4}$ gave an inseparable mixture of 11a:11b (1:5.5, 83\%) in favor of the undesired six membered ring (entry 1, table 1), and no formation of the seven membered ring derivative 11c was observed. Despite the strong $\mathrm{C}-\mathrm{Cl}$ bond of the precursor 10 , oxidative addition was taking place at $100{ }^{\circ} \mathrm{C}$. The electron withdrawing nitrogen atom activates the $\gamma$ - position, thereby facilitating the oxidative addition. $\mathrm{N}$-Heterocyclic carbenes were investigated next: the ratio dropped to $1: 2$ using the $\mathrm{IPrCl}$ ligand, and by using the $\mathrm{SIPrBF}_{4}$ ligand, the five membered ring compound 11a dominated $(1.2: 1,86 \%)$ without any ring opening observed (entries 23 , table 1). This increase prompted us to evaluate other NHC carbenes and the IAdBF 4 ligand was selective towards $\mathbf{1 1 a}$ with $31 \%$ along with the opened ring compound $11 \mathrm{c}$ in $14 \%$ as separable compounds (entry 4 , table 1), albeit in the presence of other by-products. The last ligand from the NHC series, the IPrBIANCl led to preferred formation of the six membered ring 11b (entry 5, table 1). The TADDOL based phosphonite and phosphoroamidite ligands did not yield products (entries 6-7, table 1) and in general NHC ligands proved superior in this screening, although no clear trends could be obtained with respect to their electronic and steric properties.

Scheme 3. Synthesis of Colibactin Pyrrolidono[3,4-d]pyridones via C-H activation and selective $N$-alkylation (TMSE $=$ Trimethylsilylethyl).

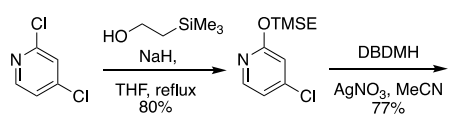

12 13
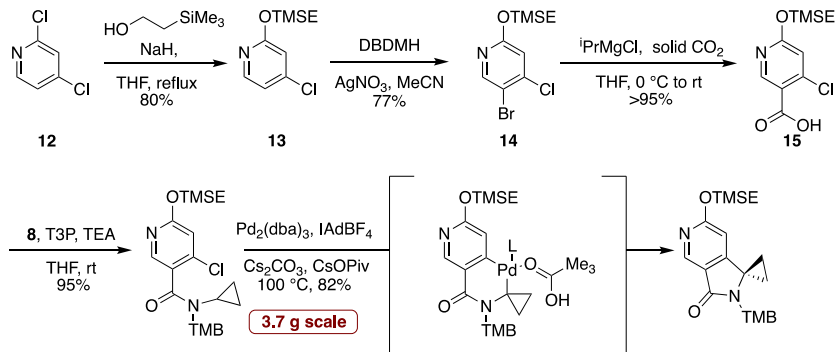

16
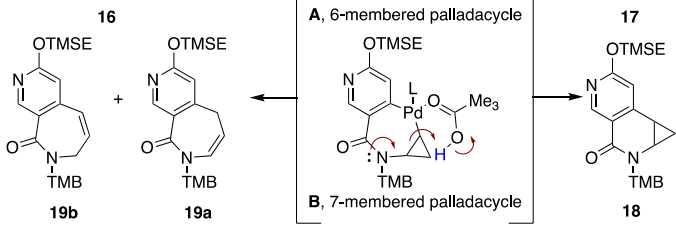

We then proceeded to the desired substrate with the insight gained from the $\mathrm{C}-\mathrm{H}$ activation screening (Scheme 3). 2,4-Dichloropyridine 12 was found as a suitable starting material and nucleophilic aromatic substitution with 2-(trimethylsilyl)ethanol provided the 2-substitued product 13 with high regioselectivity and 77\% yield.[18] Selective ortho bromination was achieved with 1,3-dibromo-5,5-dimethylhydantoin (DBDMH) and catalytic $\mathrm{AgNO}_{3}$ to yield dihalogenated pyridine 14 $(77 \%)$. Silver(I) was found to shorten the reaction time significantly. Mg halogen exchange following the procedure of Knochel[19] and subsequent quenching of the magnesiated species with solid carbon dioxide yielded the acid 15 (>95\%). Propylphosphonic anhydride (T3P) mediated coupling of the acid 15 and secondary amine 8 furnished the amide 16 in $95 \%$ yield. The Arduengo carbene IAd was selected as the optimal ligand, as it provided higher selectivity towards the desired five membered ring in this substrate (data not shown) and resulting in easier purification. On the other side, the five membered ring was dominating with the SIPrCl ligand, but other by-products were accompanying the transformation with this ligand. To this goal, cyclopropyl amide 16 was reacted with $\mathrm{Pd}_{2} \mathrm{dba}_{3}, \mathrm{Cs}_{2} \mathrm{CO}_{3}, \mathrm{CsOPiv}$, and $\mathrm{IAdBF}_{4}$ in toluene at a reaction temperature of $100{ }^{\circ} \mathrm{C}$. The desired compound was formed exclusively according to analysis of the crude reaction mixture by ${ }^{1} \mathrm{H}$ NMR spectroscopy, and after purification, bicyclic pyrrolidono[3,4d]pyridine 17 was isolated in $82 \%$ yield. The interplay between the bulky, electron-rich ligand (IAd), and a bulky organic base (pivalate) facilitates the highly challenging $\mathrm{C}\left(\mathrm{sp}^{3}\right)-\mathrm{H}$ activation. In this case, the 
formation of the six-membered palladacycle makes the ring opening impossible (intermediate A, scheme 3 ). On the other side the sevenmembered ring (intermediate $B$, scheme 3 ) can either undergo reductive elimination to 18 or ring opening towards $19 a$ or isomer $19 b$. The Charette group observed these pathways to be ligand dependent, which is supported by the results outlined herein.[14]

The mono and bisthiazole electrophiles were synthesized next (Scheme 4), as they were found in 2 and 3 . The electrophile 20b is known in the literature[20] and 20a was synthesized in two steps from the known aldehyde 21 (3 steps from literature).[21] 18 was reduced with sodium borohydride to the corresponding alcohol, and converted to chloride in presence of thionyl chloride. This procedure gives the desired electrophile 20a in $80 \%$ yield over two steps (scheme 3).[20]

\section{Scheme 4. Functionalization of the pyridone core and biological evaluation.}
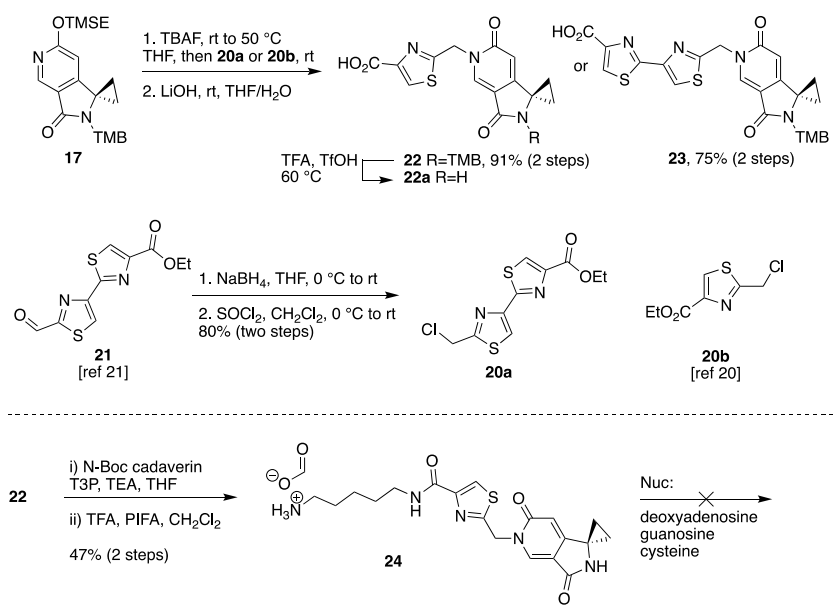

To access the pyridone core, a one pot deprotection/ alkylation protocol was developed (Scheme 4). Pyridine $\mathbf{1 7}$ was treated with tetrabutylammonium fluoride in THF at $50{ }^{\circ} \mathrm{C}$ to remove the 2 -(trimethylsilyl)ethyl protecting group and after cooling down to rt, the electrophiles 20a and 20b were directly added to the reaction mixture. Single compounds were isolated for both cases, and the thermodynamically more stable N-alkylation was determined through 2D NMR spectroscopy (HSQC, HMBC).[22] Saponification with lithium hydroxide in THF:water mixtures yielded the free acids 22 (91\%, over two steps) and 23 (75\%, over two steps). The removal of 3,4,5-trimethoxybenzyl protecting group was targeted next. The acid $\mathbf{2 2}$ showed no deprotection or decomposition in trifluoroacetic acid as solvent, but addition of trifluoromethanesulfonic acid ( 25 eq.) showed full deprotection to $\mathbf{2 2 a}$ as monitored by UHPLC-MS. This observation highlights the stability of 22, and in particular the cyclopropyl group, towards acidic conditions. We further functionalized the acid $\mathbf{2 2}$ with $\mathrm{N}$-Boc cadaverine under T3P-mediated coupling, followed by Boc and 3,4,5-trimethoxybenzyl removal using a combination of TFA and [bis(triluoroacetoxy)iodo]benzene (PIFA) to yield $\mathbf{2 4}$ (47\%, 2 steps). The addition of PIFA as oxidant was crucial for a smooth 3,4,5-TMB deprotection.[23] The additional amino functionality in $\mathbf{2 4}$ renders the compound more water soluble. Surprisingly, target cyclopropyl pyridone $\mathbf{2 4}$ resisted nucleophilic attack by deoxyadenosine, guanosine, and cysteine in water monitored by UHPLC-MS. If these systems are sufficiently conjugated, ring opening of cyclopropyl by different nucleophiles like amines or water can occur [24], but $\mathbf{2 4}$ shows an unusual high stability under the evaluated conditions and is not fitting into the common experimental observations of related electrophiles.

In summary, we present a short and straightforward synthetic route to pyridones containing 1,6-Michael acceptors that are structurally related to precolibactin metabolites. En route, we developed a highly regioselective tertiary $\mathrm{C}-\mathrm{H}$ functionalization of the cyclopropyl ring, contributing to its activation mode. Furthermore, a one-step protocol with selective $\mathrm{N}$-alkylation after protecting group removal furnished the desired Michael acceptor. Future studies might shed light into the biological activity and chemical reactivity of this compounds.

\section{ASSOCIATED CONTENT}

\section{Supporting Information}

The Supporting Information is available free of charge on the ACS Publications website.

Experimental procedures, characterization data, and copies of ${ }^{1} \mathrm{H},{ }^{13} \mathrm{C}$, and 2D NMR spectra for all new compounds (PDF)

\section{AUTHOR INFORMATION}

\section{Corresponding Author}

*E-mail: karl.gademann@uzh.ch

\section{ORCID}

Karl Gademann: 0000-0003-3053-0689

Agron Ilazi: 0000-0002-0284-2047

Address

aDepartment of Chemistry, University of Zurich, Winterthurerstrasse 190, CH 8057 Zürich

\section{Author Contributions}

The manuscript was written through contributions of all authors. All authors have given approval to the final version of the manuscript.

Notes

The authors declare no competing financial interest.

\section{ACKNOWLEDGMENT}

We acknowledge financial support by University of Zurich and the Dr. Helmut Legerlotz Foundation. We would like to thank Timea Szabo (University of Zurich) for skillful technical assistance and Dr. David Dailler and Prof. Dr. O. Baudoin (both University of Basel) for generous gifts of L1 and L2. We thank the NMR and MS service of University of Zurich for their support.

\section{REFERENCES}

1. a) Turnbaugh, P. J.; Ley, R. E.; Hamady, M.; Fraser-Liggett, C. M.; Knight, R.; Gordon, J. I. Nature 2007, 449, 804-810. b) Biteen, J. S.; Blainey, P. C.; Cardon, Z. G.; Chun, M.; Church, G. M.; Dorrestein, P. C.; Fraser, S. E.; Gilbert, J. A.; Jansson, J. K.; Knight, R.; Miller, J. F.; Ozcan, A.; Prather, K. A.; Quake, S. R.; Ruby, E. G.; Silver, P. A.; Taha, S.; Van Den Engh, G.; Weiss, P. S.; Wong, G. C. L.; Wriht, A. T.; Young, T. D. ACS Nano 2016, 10, 6-37. c) Grice, E. A.; Segre, J. A. Annu. Rev. Genomics Hum. Genet. 2012, 12, 151-170.

2. Sharon, G.; Garg, N.; Debelius, J.; Knight, R.; Dorrestein, P. C.; Mazmanian, S. K. Cell Metab. 2014, 20, 719-730.

3. a) Amieva, M, R.; El-Omar. E. M. Gastroenterology 2008, 134, 306-323. b) Schneditz, G.; Rentner, J.; Roier, S.; Pletz, J.; Herzog, K. A. T.; Bücker, R.; Troeger, H.; Schild, S.; Weber, H.; Breinbauer, R.; Gorkiewicz, G.; Högenauer, C.; Zechner, E. L. Proc. Natl. Acad. Sci. U. S. A. 2014, 111, 13181-13186.

4. Nougayrède, J.-P.; Stefan Homburg; Taieb, F.; Boury, M.; Brzuszkiewicz, E.; Gottschalk, G.; Buchrieser, C.; Hacker, J.; Dobrindt, U.; Oswald, E. Science 2006, 313, 848-851.

5. a) Vizcaino M. I.; Crawford. M. J. Nat. Chem., 2015, 7, 411-417. b) Bian X.; Plaza. A.; Zhang. Y.; Müller. R. Chem. Sci. 2015, 6, 31543160. c) Brotherton, C. A.; Wilson, M.; Byrd, G.; d) Balskus. E. P. Org. Lett. 2015, 17, 1545-1548. e) Brachmann, A. O.; Garcie, C.; Wu, V.; Martin, P.; Ueoka, R.; Oswald, E.; Piel, J. Chem. Commun. 2015, 51, 13138-13141. f) Li, Z. R.; Li, Y.; Lai. J. Y. H.; Tang, J.; Wang, B.; Lu, L.; Zhu, G.; Wu, X.; Xu, Y.; Qian, P. Y. ChemBioChem 2015, 16, 1715- 
1719. g) Li, Z. R.; Li, J.; Gu, J. P.; Lai, J. Y.; Duggan, B. M.; Zhang, W. P.; Li, Z. L.; Li, Y. X.; Tong, R. B.; Xu, Y.; Lin, D. H.; Moore, B. S.; Qian, P. Y. Nat. Chem. Biol. 2016, 12, 773-775. h) Healy, A. R.; Vizcaino, M. I.; Crawford, J. M.; Herzon, S. B. J. Am. Chem. Soc. 2016, 138, 54265432. i) Xue, M., Kim, C. S., Healy, A. R., Wernke, K. M., Wang, Z., Frischling, M. C., Shine, E. E., Wang, W., Herzon, S. B., Crawford, J. M. Science 2019, 365, No. eaax2685. j) Li, Zh. R.; Li, J.; Cai, W.; Lai, J. Y. H.; McKinnie, S. M. K.; Zhang, W. P.; Moore, B. S., Zhang, W.; Qian, P. Y. Nat. Chem. 2019, 11, 880-889. k) Healy, A. R.; Nikolayevskiy, H.; Patel, J. R.; Crawford, J. M.; Herzon, S. B. J. Am. Chem. Soc. 2016, 138, 15563-15570.

6. Brotherton, A. C.; Balskus, E. P. J. Am. Chem. Soc. 2013, 135, 33593362 .

7. Reviews and perspective on (pre)-colibactin a) Balskus, E. P. Nat. Prod. Rep. 2015, 32, 1534-1540. b) Healy, A. R.; Herzon, S. B. J. Am. Chem. Soc. 2017, 139, 14817-14824. c) Faïs, T., Delmas, J., Barnich, N., Bonnet, R.; Dalmasso, G. Toxins 2018, 10, 151. d) Werneke, K. M.; Xue, M.; Tirla, A.; Kim, C. S.; Crawford, J. M.; Herzon. S. B. Bioorg. Med. Chem. Lett. 2020, 30, 127280

8. a) Schmid, F.; Bernasconi, M.; Jessen, H. J.; Pfaltz, A.; Gademann K. Synthesis, 2014, 46, 864-870. b) Jessen, H. J.; Schumacher, A.; Shaw, T.; Pfaltz, A.; Gademann, K. Angew. Chem. Int. Ed. 2011, 50, 4222-4226. c) Dash, U.; Sengupta, S.; Sim, T. Eur. J. Org. Chem. 2015, 3963-3970. d) Schröder, P.; Förster, T.; Kleine, S.; Becker, C.; Richters, A.; Ziegler, S.; Rauh, D.; Kumar, K.; Waldmann, H. Angew. Chem. 2015, 127, 12575-12580.

9. a) Jessen, H. J.; Gademann, K. Nat. Prod. Rep. 2010, 27, 11681185. b) Witherington. J.; Bordas. V.; Gaiba, A.; Green, P. M.; Naylor.; Parr, N.; Smith, D. G.; Takle, A. K.; Ward, R. W. Bioorg. Med. Chem. Lett. 2016, 16, 2256-2259. c) Jia, H.; Song, Y.; Yu, J.; Zhan, P.; Rai, D.; Liang, X.; Ma, C.; Liu, X. Eur. J. Med. Chem. 2017, 136, 144-153 10. a) Jackson, P. A.; Widen, J. C.; Harki, D. A.; Brummond, K. M. J. Med. Chem. 2017, 60, 839-885. b) Gehringer, M.; Laufer, S. A.; J. Med. Chem. 2019, 62, 5673-5742.
11. Review on CMD-mechanism a) Lapointe, D.; Fagnou, K. Chem. Lett. 2010, 39, 1118-1126. b) Baudoin, O. Chem. Soc. Rev. 2011, 40 4902-4911. c) Pedroni, J.; Cramer, N. Chem. Commun. 2015, 51, 17647-17657.

12. a) Chen. D. Y. K.; Youn, S. W. Chem. Eur. J. 2012, 18, 9452-9474. b) Jazzar, R.; Hitce, J.; Renaudat, A.; Sofack-Kreutzer, J.; Baudoin, 0. Chem. Eur. J. 2012, 16, 2645-2672. c) Karimov, R. R.; Hartwig, J. F.; Angew. Chem. Int. Ed. 2018, 57, 4234-4241.

13. a) Lefrance, M.; Gorelsky, S. I., Fagnou, K. J. Am. Chem. Soc. 2017, 129, 14570-14571. b) Rousseaux, S.; Liégault, B.; Fagnou, K. Chem. Sci. 2012, 3, 244-248.

14. Ladd, C. L.; Roman, D. S.; Charette, A. B. Tetrahedron 2013, 69, $4479-4487$.

15. Pedroni, J.; Saget, T.; Donets, P. A.; Cramer, N. Chem. Sci. 2015, 6, 5164-5171.

16. Abdel-Magid, A. F.; Garson, K. G.; Harris, B. D.; Maryanoff, C. A.; Shah, R. D. J. Org. Chem. 1996, 61, 3849-3862.

17. Holstein, P. M.; Dailler, D.; Ventourout, J.; Shaya, J.; Millet, A.; Baudoin, O. Angew. Chem. Int. Ed. 2016, 55, 2805-2809.

18. Campeau, L. C.; Dolman, S. J.; Gauvreau, D.; Corley, E.; Liu, J.; Guidry, E. N.; Ouellet, S. G.; Steinhuebel, D.; Weisel, M.; O’Shea, P. D. Org. Process Res. Dev. 2011, 15, 1138-1148.

19. Boymond, L.; Rottländer, M.; Cahiez, G.; Knochel, P. Angew. Chem. Int. Ed. 1998, 37, 1701-1703

20. Brindisi, M.; Maramai, S.; Grillo, A.; Brogi, S.; Butini, S.; Novellino, E.; Campiani, G.; Gemma, S. Tetrahedron. Lett. 2016 57, 920 923.

21. a) Aulakh, V. S.; Ciufolini, M. A. J. Org. Chem. 2009, 74, 57505753. b) Aulakh, V. S.; Ciufolini, M. A. J. Am. Chem. Soc. 2011, 133, 5900-5904.

22. Mayr, H.; Breugst, M. J. Am. Chem. Soc. 2010, 132, 15380-15389.

23. Watanabe, K.; Katoh, T. Tetrahedron. Lett. 2011 52, 5395-5397. 24. De Meijere, A. Angew. Chem. Int. Ed. 1979, 18, 809-826. 